\title{
Prevalence and economic losses resulting from parasitic zoonosis on swine and ruminants in Ouagadougou abattoir (Burkina Faso)
}

\author{
Laibané Dieudonné DAHOUROU ${ }^{1 *}$, Canésius NDAYIKEZA², Madi SAVADOGO ${ }^{3}$ and \\ Oubri Bassa GBATI ${ }^{3}$
}

\author{
${ }^{1}$ Université de Dédougou (Burkina Faso), Institut des Sciences de l'Environnement et du Développement \\ Durable (ISEDR), BP 176 Dédougou, Burkina Faso. \\ ${ }^{2}$ Institut des sciences agronomiques du Burundi (ISABU), Bujumbura, Burundi. \\ ${ }^{3}$ Ecole Inter-Etats des Sciences et Médecine Vétérinaire (EISMV) de Dakar, BP 5077 Dakar, Sénégal. \\ *Corresponding author; E-mail: d_dahourou@yahoo.fr /Tel: +22670653744 / +226741761 20.
}

\begin{abstract}
Cysticercosis and fasciolosis are zoonosis with public health and economic importance. A retrospective study was conducted with the objective to determine the prevalence and economic losses associated with meat condemnation in Ouagadougou abattoir due to two parasitic zoonosis: fasciolosis and cysticercosis. The meat inspection register was sifted through to collect data on animals slaughtered in the abattoir between 2007 and 2013. Prices of carcasses and organs have been requested from stakeholders in the meat industry. The prevalence and economic losses associated with animal fasciolosis and cysticercosis were calculated. The overall prevalence of fasciolosis and cysticercosis were $0.41 \%$ and $0.17 \%$, respectively. The highest prevalence of fasciolosis was observed in cattle $(0.82 \%)$, while the highest rate of cysticercosis was observed in pigs $(0.22 \%)$. For both fasciolosis and cysticercosis, the highest number of condemnation was observed during the dry season. Total economic losses due to fasciolosis stemming from seizure of liver and carcass weight loss were estimated at XOF $142068284(\$ 258,423)$ while losses related to cysticercosis-infected organs and carcasses was estimated at XOF 6286000 (\$11,434 USD). This study highlights the impact of these diseases in Burkina Faso and proves that the country's population is facing riks of contamination.
\end{abstract}

(C) 2018 International Formulae Group. All rights reserved.

Keywords: Public heath, cysticercosis, meat, swine, cattle, Burkina Faso

\section{INTRODUCTION}

Zoonosis diseases represent around $61 \%$ of all known human infectious diseases (Desta, 2016). They have a significant impact on public health, animal health and high economic significance in African countries. These diseases affect poor and marginalized people in developing countries who live in close contact with animals, often in unsanitary conditions and in areas where coverage of health services is inadequate (Schelling et al., 2007). Transmission of pathogens from livestock to humans can occur through the consumption of contaminated meat or milk (Vikou et al., 2018; Millogo et al., 2018) or through direct or indirect contact as mentioned by Taylor et al., (2001). Many kinds of pathogens such as virus, bacteria, fungi or parasite can cause zoonosis. Abattoirs play an important role in the surveillance of 
zoonotic diseases in African countries by interdicting infected meat from human. In fact, parasitic zoonosis can be diagnosed in animals at the Abattoirs. Zoonosis like fasciolosis and cysticercosis are the main zoonotic parasitic diseases found in Abattoirs and responsible for carcass and organ seizure (Elmonir et al., 2015). Consequently, these diseases cause significant losses in animal production (Addis, 2017). Abattoir meat inspection can therefore be used to monitor the status of these diseases in animals (Mellau et al., 2010). In addition, it plays an important role in helping to prevent various diseases transmittable to humans through meats unfit for human consumption (Alton et al., 2010). Several studies have revealed the existence of parasitic zoonosis in humans in Africa (Nossair and Abdella, 2014).

In developing countries like Burkina Faso, where animal production is an important segment of the agro-pastoral economy, it is necessary to continue monitoring the status of parasitic zoonosis to determine their prevalence and economic impacts. This monitoring can help to devise and prioritize diseases control strategies that a country can implement to protect public and animal health. However, data on the prevalence of parasitic zoonosis transmitted through meat and economic losses associated with them is very poor in Burkina Faso, mainly from abattoir. This research seeks to address this data shortage. Its objective was to evaluate the prevalence and economic losses due to the main parasitic zoonosis found in Ouagadougou abattoir in Burkina Faso.

\section{MATERIALS AND METHODS}

\section{Study area}

Our study was conducted in Ouagadougou, the capital-city of Burkina Faso. Ouagadougou is home to some 2.2 million inhabitants and is located at $12^{\circ} 21 ' 56$ " $\mathrm{N}$ and $1^{\circ} 32^{\prime} 01^{\prime \prime} \mathrm{W}$ and is the administrative, cultural and economic hub of the country. More specifically, the study was conducted at the refrigerated abattoir of Ouagadougou located at the North of the town. This abattoir is fully-fledged meat production industry for the local market and for neighbouring countries such as Côte d'Ivoire and Ghana (Burkina Faso / MRAH, 2007).

\section{Post-mortem detection of parasitic diseases}

Systematic meat inspection is carried out by a veterinarian. The diagnosis of carcass and offal lesions was made by visual inspection, palpation or, as appropriate, incision of suspected cases according to Food and Agriculture Organization (FAO) meat inspection standards (Burkina Faso / MRAH, 2012). Depending on the severity of the risk to consumers or because of repugnance, carcasses or offal with parasitic lesions are condemned and recorded according to the reason for condemnation.

\section{Study design}

Data was gathered through a retrospective study. We tapped into information from the electronic database of official meat inspection records in the Ouagadougou abattoir. Such information was related to the total number of animals slaughtered by species, the number of organs or carcasses seized and the reasons for these seizures during the period between January 2007 and December 2013. From this database, we selected data based on the total monthly and annual number of pigs and cattle slaughtered, the number of organs and carcasses seized and the reasons for the seizure. These data were used to calculate the prevalence and economic losses.

\section{Calculation of the overall prevalence of parasitic diseases studied}

The prevalence was calculated according to Thrusfield (2007). So, the overall prevalence of different parasites studied was estimated by dividing the total number of animals infected for each parasite (animals with organs or carcasses condemned) during the study period by the total number of animals slaughtered during the same period and then multiplied by 100 . 
Estimated economic losses associated with the diseases studied

Direct losses due to carcass / organ condemnation

Direct losses were calculated using a modified version of the formula of Elmonir et al. (2015). They used the formula EL = NA * $\mathrm{PM} * \mathrm{CM}$ with (EL: economic losses, NA: number of animals slaughtered; PM: prevalence of the pathology; CM: average cost). By modifying this basic formula, the following equation was used for the losses calculation.

$\mathrm{EL}=\mathrm{NC} * \mathrm{AC}$

$\mathrm{EL}=$ Estimated economic loss during study period; $\mathrm{NC}=$ Number of carcasses or organs condemned during the study period; $\mathrm{AC}=$ Average cost of organ or carcass at Ouagadougou slaughterhouse market in August 2017. To obtain carcass prices, we interviewed five different butchers at the Ouagadougou slaughterhouse. On the other hand, the retail price of the various organs was obtained by interviewing five retail butchers in the market of Bendogo. We obtained the average cost by calculating the average of the five prices obtained.

Economic losses due to weight loss of carcasses associated with fasciolosis

These losses were calculated according to Swai and Ulicky's (2009) method with $10 \%$ carcass weight loss due to fasciolosis in infected animals. As a result, the final equation was as follows:

$\mathrm{EL}=\mathrm{ECs} *(\mathrm{Coy} * 10 \%) * \mathrm{Roz}$

Where EL $=$ Economic loss estimated during the study period; Ecs = Number of animal slaughtered during the study period; Coy $=$ Average cost of single animal carcass during the study period; Roz $=$ Prevalence of animal fasciolosis during the study period.

The various costs of losses were expressed in XOF and then converted into US dollars (USD). The exchange rate considered was XOF $549.75=$ USD 1 .

\section{Data management and analysis}

The data collected were entered, recorded and stored in Microsoft excel spread sheets version 2013. The results have been synthesized and shown in tables and graphics using Excel.

\section{RESULTS}

Prevalence

A total of 446,500 cattle and 62,311 pigs were slaughtered and examined during this study period as shown in Table 1 . The prevalence of fasciolosis among cattle, goats and sheep at Ouagadougou slaughterhouse during the 7-years of the study period was $0.41 \%$. Cattle turn to be more infested with flukes with an overall prevalence of $0.82 \%$ (Table 1).

A total of 508811 animals (cattle and pigs) were slaughtered and examined during this study period as shown in Table 2 . The prevalence of bovine and porcine cysticercosis at Ouagadougou slaughterhouse during the study period was $0.17 \%$. Porcine cysticercosis was most prevalent $(0.22 \%)$ than bovine cysticercosis (Table 2).

\section{Seasonal and annual variation of the number of condemned carcass or organs}

During the study period, the number of carcass or organs condemned because of parasitic zoonosis was higher during the dry season. For bovine cysticercosis, the most important organ condemnation was noticed during dry season of 2012 (Figure 1). For porcine cysticercosis, the peak carcass condemnation was observed during dry season of 2011 (Figure 2). Regarding fasciolosis, the most important organ condemnation was during dry season of 2012 (Figure 3).

\section{Economic losses}

Economic losses estimated for fasciolosis in slaughtered animals in Ouagadougou abattoir during this study period are listed in Table 3. A total of XOF $142,068,284(\$ 258,423)$ was the monetary loss due to fasciolosis in cattle (XOF 141789575 ) and small ruminant (XOF 278 709).

For cysticercosis, a total of XOF $6286000(\$ 11,434)$ were the monetary loss due to the disease in cattle (XOF 3887500 ) and pigs (XOF 2398 500). 
Table 1: Overall prevalence of fasciolosis in the slaughtered animals at the Ouagadougou slaughterhouse.

\begin{tabular}{lllc}
\hline Species & Animals slaughtered & $\begin{array}{l}\text { Number of condemned } \\
\text { carcasses or organs }\end{array}$ & $\begin{array}{l}\text { Prevalence } \\
(\%)\end{array}$ \\
\hline Cattle & 446500 & 3647 & 0,82 \\
Small ruminants & 463224 & 70 & 0,02 \\
\hline Total & 909724 & 3717 & 0,41 \\
\hline
\end{tabular}

Table 2: Overall prevalence of porcine and bovine cysticercosis at Ouagadougou slaughterhouse.

\begin{tabular}{lllll}
\hline Species & Animals slaughtered & $\begin{array}{l}\text { Number of condemned carcasses } \\
\text { organs }\end{array}$ & or & Prevalence (\%) \\
\hline Cattle & 446500 & 714 & 0,16 \\
Pigs & 62311 & 139 & 0,22 \\
\hline Total & 508811 & 853 & 0,17 \\
\hline
\end{tabular}

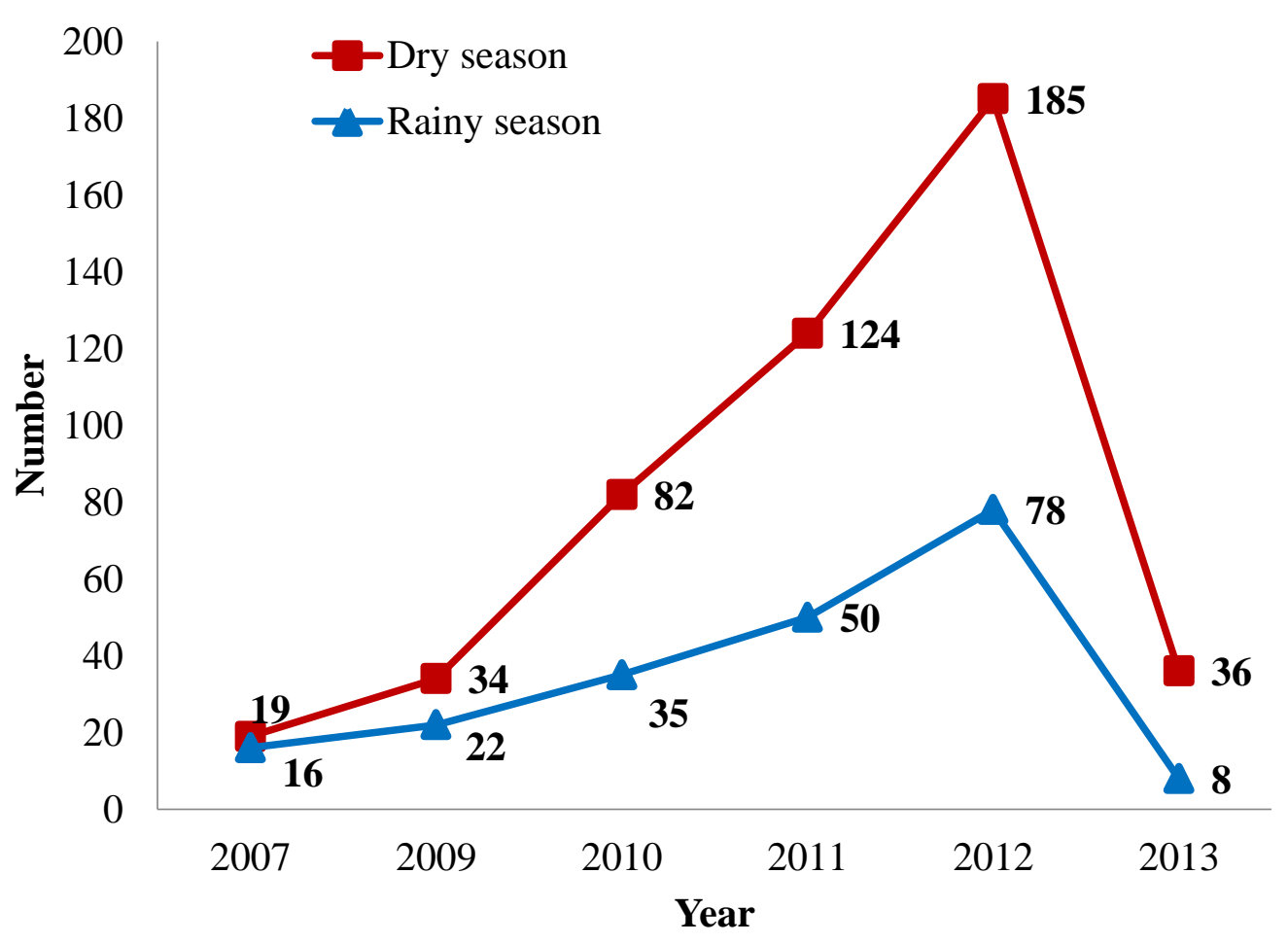

Figure 1 : Seasonal and annual variation of organs condemned because of bovine cysticercosis. 


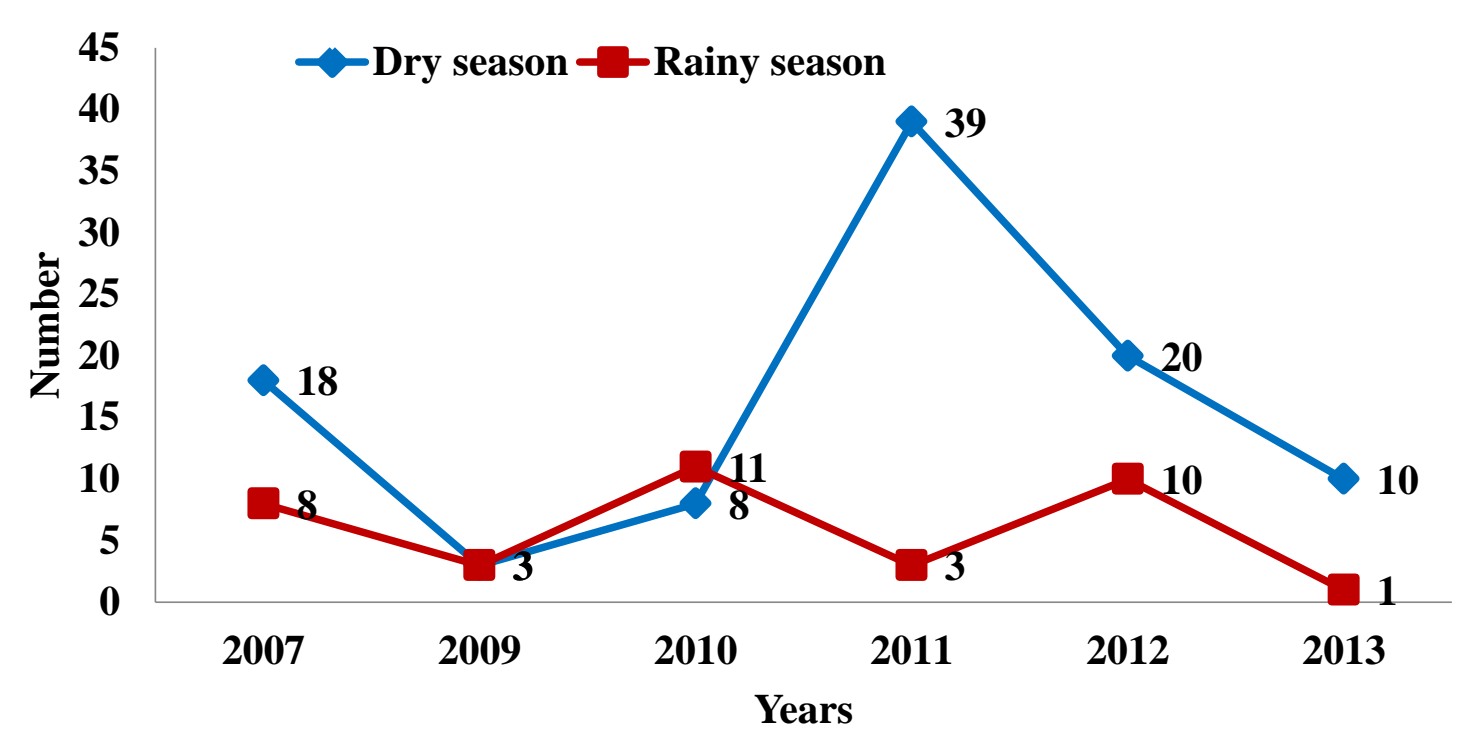

Figure 2 : Seasonal and annual variation of carcass condemnation because of porcine cysticercosis.

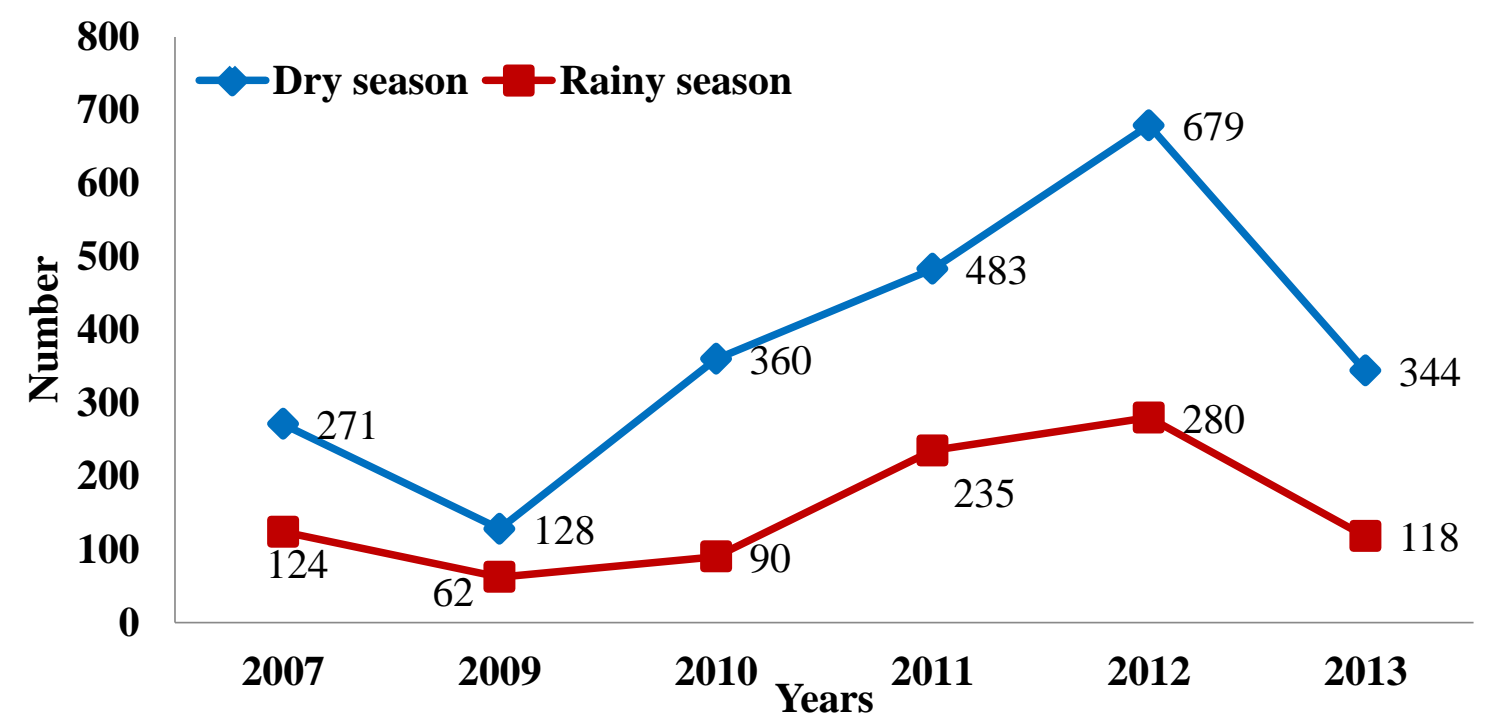

Figure 3 : Seasonal and annual variation of organ condemnation because of fasciolosis

Table 3: Economic losses associated with fasciolosis at Ouagadougou slaughterhouse.

\begin{tabular}{lllll}
\hline & \multicolumn{2}{l}{ Economic losses } & Total & \\
\cline { 2 - 5 } & Cattle & Small ruminants & XOF & USD \\
\hline Liver condemnation & 21882000 & 105000 & 21987000 & 39994,54 \\
Weight loss & 119907575 & 173709 & 120081284 & 218428,89 \\
\hline Total & 141789575 & 278709 & 142068284 & 258423,44 \\
\hline
\end{tabular}




\section{DISCUSSION}

\section{Limitations of the Study}

Our study aimed at determining the prevalence and evaluating the economic losses associated with parasitic zoonosis. This determination was based on records of meat condemnation made at the Ouagadougou abattoir. The prevalence of parasitic diseases obtained in this study should be interpreted with caution. In fact, animals with minor infestations were not registered because they were not condemned. Therefore, the actual prevalence of parasitic infestations in the country could be well beyond the values we have found.

It should also be noted that the true assessment of the economic losses associated with the parasitic diseases studied is more complex and involves complex parameters such as mortality rates, effects of food misallocation and the costs of anthelminthic treatments caused by these diseases. In this study, these parameters were not used for the calculation of economic losses. Therefore, the economic losses estimated in this study are likely to be lower than actual losses and should be carefully interpreted

\section{Prevalence of parasitic diseases studied}

The overall prevalence of parasitic zoonosis in this study was $0.41 \%$. This prevalence is lower than those obtained in Egypt where Elmonir et al. (2015) found a prevalence of $0.76 \%$. In addition, it was low compared to the prevalence found in Saudi Arabia by Shalaby et al. (2011) or in Iran (Borji et al., 2012) which were $2.63 \%$ and $3.7 \%$ respectively. The overall prevalence of fasciolosis was $0.41 \%$ with $0.82 \%$ and $0.02 \%$ respectively for cattle and small ruminants. This observed difference between cattle and small ruminants may be explained by genetic differences between these two categories of ruminants that would confer a higher natural resistance of small ruminants to infestations (Uduak, 2014). In addition, small ruminants and especially goats graze selectively. This feeding behaviour would reduce exposure to the infesting metacercariae that are abundant on grasses found around wetlands. This prevalence of fasciolosis was lower compared to data found in studies conducted in Egypt (Youssef and Uga, 2014) and Nigeria (Uduak, 2014). The prevalence of bovine fasciolosis found in these countries was $3.5 \% ; 1.72 \%$ and $8 \%$ respectively. This difference in the prevalence of fasciolosis can be attributed to many factors such as differences in resistance to infection, grazing habits and animal breeds as well as differences in local climatic conditions (Amarasinghe and Kumara, 2007) that may influence the flukes development cycle (Chanie and Bengashaw, 2012). In the present study, the overall prevalence of cysticercosis in slaughtered animals was $0.17 \%$ with $0.16 \%$ and $0.22 \%$ respectively in cattle and pigs. This difference in the prevalence of cysticercosis between cattle and pigs could be explained by the coprophagic behaviour of pigs and their breeding mode in Burkina Faso. In the country, like in Benin (Djimenou et al., 2017) about 98\% of pigs are bred according to a traditional system where animals are bred by poor rural communities without adequate sanitation (FAO, 2012). Wandering pigs may consume human faeces potentially infective to pigs. In fact, children tend to defecate more frequently in pigsty or around houses (FAO, 2012). The prevalence of bovine cysticercosis obtained is low compared with those obtained in Nigeria $(2.67 \%)$ by Rabi and Jegede (2010) and in Ethiopia (1.2\%) by Edao et al. (2017). In addition, the prevalence of porcine cysticercosis $(0.22 \%)$ is similar to that found in southern Senegal $(0.1 \%)$ and Gambia $(0.2 \%)$ by Secka et al. (2010). However, it is low compared to those obtained in other African countries such as Madagascar (4.6\%) (Porphyre et al., 2015); Benin (0.87\%) (Goussanou et al., 2014); Kenya (5.6\%) (Eshitera et al., 2012) using meat inspection.

\section{Economic losses associated with parasitic diseases studied}

According to our data, animal fasciolosis had a high economic significance in Burkina Faso. In fact, estimates of losses related to seizures of liver due to fasciolosis are estimated at XOF 142,068,284 (USD 
258,423.44). Earlier work has estimated the annual losses associated with this animal disease in many parts of Africa and the world. These losses are estimated at 18,000 USD in Tanzania (Mwabonimana et al., 2009), to 13,367.72 USD in central Ethiopia (Regassa et al., 2012). The variations of losses obtained could be due to the differences in the local economic realities, the durations of study and the number of animals concerned by these different studies. Despite the variability of these results, it is important to note that fasciolosis causes significant losses in animal production around the world.

Despite the significant high losses in animal production losses associated with fasciolosis, it does not represent the actual losses due to fasciolosis in Burkina Faso. Indeed, the minor zoonotic nature of this parasitic pathology gives it an impact much heavier. Human fasciolosis is classified as one of the most neglected tropical zoonosis (Welburn et al., 2015). Thus, the actual economic losses of this disease are magnified by its burden on public health although it is often overlooked. The morbidities associated with human fasciolosis significantly contribute to poor quality of life, reduced life expectancy and production, since the adult worm can live for more than 10 years in a suitable host such as man (Fentie et al., 2013).

As for the losses due to animal cysticercosis, this study has shown through Table 3 that these losses are estimated at XOF $2,398,500(\$ 4,362)$ for porcine cysticercosis and XOF $3,887,500(\$ 7,071)$ for bovine cysticercosis. Work in some African countries has estimated losses from condemnation due to porcine cysticercosis at XOF $25,715,448$ in the abattoir of Bobo-Dioulasso $(\$ 41,565.9)$ in Burkina Faso (Dahourou et al., 2016) and $\$ 29,035$ at the Kumasi abattoir in Ghana (Atawalna et al., 2015). However, these economic losses of animal production represent almost nothing compared with the losses related to the reduction of the cost of infested animals and the indirect losses (costs of treatments, diagnosis, social stigmatization, impaired quality of life) associated with $T$. solium human neurocysticercosis often implicated in the occurrence of epilepsy in humans (Winkler et al., 2009). The zoonotic appearance of cysticercosis gives it more important impact than the simple direct losses related to animal productions. Indeed, cysticercosis has so far been considered a neglected tropical zoonosis (Murrell et al., 2005). In a developing country like Burkina Faso where factors promoting the development of human taeniasis/cysticercosis do exist, the socio-economic impact of this pathology is considerable.

\section{Conclusion}

This work was carried out to assess the prevalence and economic losses associated with cysticercosis and fasciolosis in Ouagadougou slaughterhouse. It has shown that parasitic zoonosis is present in animals slaughtered at the abattoir of Ouagadougou. The overall prevalence of these pathologies was evaluated at $0.47 \%$. Although this prevalence rate is relatively low, the impact of these pathologies on the economy is not at all insignificant. They are responsible for losses estimated at about XOF 20 million $(\$ 36,380)$ each year. Moreover, the impact of these diseases on public health should not be neglected. It is particularly alarming because, unlike most large human settlements that consume controlled meat produced by abattoirs, some rural populations consume meat from uncontrolled slaughter areas that are found in some rural areas in Burkina Faso. Therefore, measures must be adopted to protect public and animal health in Burkina Faso. Taking it forward from this point, further studies should be undertaken in at-risk populations such as farmers and consumers of raw or undercooked meat to determine the prevalence of these parasites in humans

\section{COMPETING INTERESTS}

Authors declare they have no competing interests.

\section{AUTHORS' CONTRIBUTIONS}

DLD initiated the study and penned the rough draft. DLD, CN and MS collected data and contributed to data analysis and economic 
losses calculation. OBG, $\mathrm{MS}$ and $\mathrm{CN}$ reviewed the manuscript.

\section{ACKNOWLEDGEMENTS}

Authors wish to express their heartfelt gratitude to all veterinarians, administrative staff and butchers at Ouagadougou slaughterhouse for their unstinting support and inputs in this study. We would also like to thank $\mathrm{Mr}$ Arounan Sanan for his high contribution

\section{REFERENCES}

Addis AB, 2017. Causes of organ condemnation and economic loss of cattle in developing countries. Review. Int J Eng Dev Res, 5(1): 776-796.

Alton GD, Pearl LD, Bateman KG, McNab WB, Berke O. 2010. Factors associated with whole carcass condemnation rates in provincially-inspected abattoirs in Ontario 2001-2007: implications for food animal syndromic surveillance. BMC Vet. Res., 6: 42. DOI: https://doi.org/10.1186/1746-6148-6-42

Amarasinghe LD and Kumara HLNN, 2007. Effect of rainfall and temperature on liver and rumen fluke infestations of bovines in Sri Lanka. Int. J. Biol. Chem. Sci., 1(3): 229-236.

Atawalna J, Ewura S, Mensah M. 2015. Prevalence and Financial Losses Associated with Porcine Cysticercosis in the Kumasi Metropolis of Ghana. Int. J. Lives. Res., 5(9): 21-26. DOI: 10.5455/ijlr.20150825044155.

Borji H, Azizzadeh M, Kamelli M. 2012. A retrospective study of abattoir condemnation due to parasitic infections: Economic importance in Ahwaz, Southwestern Iran. J. Parasitol., 98: 954-957. DOI: https://doi.org/10.1645/GE-2988.1.

Burkina Faso / MRAH. 2007. Rapport sur l'analyse de la filière bétail-viande au Burkina Faso. MRAH: Ouagadougou.
Chanie M, Bengashaw S. 2012. Assessment of the economic impact and prevalence of ovine fasciolosis in Menz Lalo Midir District, Northeast Ethiopia. Vet. World., 5: 261-264. DOI: 10.5455/vetworld.2012.261-264.

Dahourou LD, Gbati OB., Milogo A., Roamba CR, Pangui LJ. 2016. Evaluation de l'impact économique de la cysticercose porcine et humaine au Burkina Faso. Rev Afr Sante Prod Anim., 14 (3-4): 67-72.

Desta AH. 2016. One Health: an integrated approach for disease prevention and control in pastoral areas in Ethiopia. J. Health Med. Nur., 22: 2422-8419.

Djimenou D, Adoukonou-Sagbadja $\mathrm{H}$, Koudande DO, Chrysostome CAAM, Hounzangbe-Adote SM, Agbangla C, 2017. Caractéristiques sociodémographiques des éleveurs de porcs (Sus Scrofa domesticus) et structure du cheptel porcin au Sud du Bénin. Int. J. Biol. Chem. Sci., 11(5): 2177-2193.

DOI: https://dx.doi.org/10.4314/ijbcs.v11i5.19

Edao A, Dima FG, Deressa FB. 2017. Prevalence of bovine cysticercosis and status of human taeniasis in and around Asella Town, Tiyo Woreda, South East Ethiopia. Glob J Med Res., 23: 678-785.

Elmonir W, Mousa W, Sultan K. 2015. The prevalence of some parasitic zoonoses in different slaughtered animal species at abattoir in the mid-Delta of Egypt; with special reference to its economic implication. Alexandria J. Vet. Sci., 47: 97-103. DOI: 10.5455/ajvs.204290.

Eshitera, E, Githigia SM, Kitala P. 2012. Prevalence of porcine cysticercosis and associated risk factors in Homa Bay District, Kenya. BMC Vet Res., 8: 234. DOI: https://doi.org/10.1186/1746-61488-234.

FAO. 2012. Secteur porcin Burkina Faso. Revues Nationales de l'élevage de la 
division de la production et de la santé animales de la FAO : Rome.

Fentie T, Erqou S, Gedefaw M, Desta A. 2013. Epidemiology of human fascioliasis and intestinal parasitosis among schoolchildren in Lake Tana Basin, northwest Ethiopia. Trans. R. Soc. Trop. Med. Hyg., 107(8):480-486. DOI: https://doi.org/10.1093/trstmh/trt056.

Goussanou JSE, Korsak N, Saegerman C, Youssao AKI, Azagoun E, Farougou S, Kpodekon MT. 2014. Assessment of routine inspection method for diagnostic of porcine cysticercosis in south east Benin by using meat inspection records and Ag-ELISA test. Int. J. Anim. Vet. $A d v$.; 6(2): 80-86.

Mellau LSB, Longa HE, Karimuribu ED. 2010. A Slaughter house survey of liver lesion in slaughter cattle, sheep and goats at Arusha, Tanzania. J. Vet. Sci.; 3: 179188.

DOI:

10.3923/rjvs.2010.179.188.

Millogo V, Sissao M, Ouedraogo GA, 2018. Qualité nutritionnelle et bactériologique des échantillons de quelques produits laitiers locaux de la chaîne de production au Burkina Faso. Int. J. Biol. Chem. Sci. 12(1): 244-252. DOI: https://dx.doi.org/10.4314/ijbcs.v12i1.19

Murrell KD, Dorny P, Flisser A, Geerts S, Kyvsgaard NC, Mcmanus D, Nash T, Pawlowski Z. 2005. Guidelines for the surveillance, prevention and control of taeniosis/cysticercosis. OIE/WHO/FAO: Paris.

Mwabonimana MF, Kassuku AA, Ngowi HA, Mellau LSB, Nonga, HE, Karimuribo ED.2009. Prevalence and economic significance of bovine fasciolosis in slaughtered cattle at Arusha abattoir, Tanzania. BMC Vet Res., 26: 68-74. DOI: $10.4314 /$ tvj.v26i2.53804.
Nossair M, Abdella D. 2014. Serological detection of Fasciola hepatica antibodies among cattle and human in Behera Province, West Delta, Egypt. Alexandria J. Vet. Sci. 40: 16-23. DOI: 10.5455/ajvs.48309.

Porphyre V, Rasamoelina-Andriamanivo H, Rakotoarimanana A, Rasamoelina O, Bernard C, Jambou R, Cardinale E. 2015. Spatio-temporal prevalence of porcine cysticercosis in Madagascar based on meat inspection. Parasit Vectors, 8(1): $391 . \quad$ DOI: https://doi.org/10.1186/s13071-0150975-2.

Rabi B, Jegede O. 2010. Incidence of bovine cysticercosis in Kano state, northwestern, Nigeria. Bayero J. Pure Appl Sci., 3(1): 100-103. DOI: http://dx.doi.org/10.4314/bajopas.v3i1.5 8729.

Regassa A, Woldemariam T, Demisie S, Moje N, Ayana D, Abunna F. 2012. Bovine fasciolosis: coprological, abattoir survey, and financial loss due to liver condemnation in Bsihoopin municipal abattoir, central Ethiopia. Eur $J$ Biological Sci., 4(3): 83-90. DOI: 10.5829/idosi.ejbs.2012.4.3.63180.

Schelling E, Wyss K, Diguimbaye C, Bechir M, Taleb MO, Bonfoh B, Tanner M, Zinnstag J. 2007. Towards integrated and adapted health services for nomadic pastoralists. In Handbook of Transdisciplinary Research, Hirsch Hadorn G, Hoffmann-Reim H, BiberKlemm S, Grossenbacher W, Joye D, Pohl C, Wiesmann U, Zemp E (eds). Springer: Heidelberg; 277-291.

Secka A, Marcotty T, De Deken R., Van Marck E, Geertz S. 2010. Porcine cysticercosis and risk factors in The Gambia and Senegal. J Parasitol Res., 2010: $\quad 823892 . \quad$ DOI: http://dx.doi.org/10.1155/2010/823892. 
Shalaby IMI, Banaja AA, Jamoom MB. 2011. A comparative study on the prevalence of some parasites of animals slaughtered at new Taif abattoir. Glob Vet., 6: 295-299.

Swai E, Ulicky E. 2009. An evaluation of the economic losses resulting from condemnation of cattle livers and loss of carcass weight due to Fasciolosis: a case study from Hai town abattoir, Kilimanjaro region, Tanzania. Livestock Res. Rural Develop., 21: 186.

Taylor LH, Latham SM, Woolhouse ME. 2001. Risk factors for human disease emergence. Philos Trans $R$ Soc Lond B Biol Sci., 356: 983-989. DOI: 10.1098/rstb.2001.0888.

Thrusfield M. 2007. Veterinary Epidemiology (3rd edn). Blackwell Publishing: Ames.

Uduak A. 2014. Incidence of Bovine Fasciolosis and its Economic Implications at Trans-madi Abattoir Port-Harcourt, Nigeria. Acta Parasitol
Glob., 5: 206-209. DOI: 10.5829/idosi.apg.2014.5.3.85139.

Vikou R, Aplogan LG, Ahanhanzo C, BabaMoussa L, Gbangboche AB, 2018. Prévalence de la brucellose et de la tuberculose chez les bovins au Bénin. Int. J. Biol. Chem. Sci., 12(1): 120-128. DOI:

https://dx.doi.org/10.4314/ijbcs.v12i1.9.

Welburn SC, Beange I, Ducrotoy MJ, Okello AL. 2015. The neglected zoonose, the case for integrated control and advocacy. Clin Microbiol. Infect., 21(5) : 433-443. DOI: 10.1016/j.cmi.2015.04.011.

Winkler AS, Willingham AL 3rd, Sikasunge CS, Schmutzhard E. 2009. Epilepsy and neurocysticercosis in sub-Saharan Africa. Wiener Klinische Wochenschrift, 121(3): 3-12. DOI:10.1007/s00508-009$1242-3$

Youssef A, Uga S. 2014. Review of parasitic zoonoses in Egypt. Trop. Med. Health., 42: 3- 4. DOI: 10.2149/tmh.2013-23. 